\title{
YOUNG MUSKRATS TRANSPORTED UNDERWATER BY NURSING MOTHER
}

\author{
WILLIAM J. WALLEY, 19 Edgar Avenue, Dauphin, Manitoba. R7N 0R4
}

In 1985 the Science Department of the Dauphin Regional Comprehensive Secondary School conducted its spring Biology field trip to Riding Mountain National Park on 27 May. In the early afternoon the author and a class of 30 students emerged from spruce - aspen forest and proceeded eastward along the top of an old Beaver dam which still held a sizable impoundment of water, the level of which was about $0.75 \mathrm{~m}$ below the top of the dam.

The group was engaged in identifying aquatic invertebrates along the dam when a Muskrat swam parallel to the dam in an easterly direction $3 \mathrm{~m}$ out and about $0.5 \mathrm{~m}$ below the surface. As we watched we were surprised to see at least four young attached to the female's inguinal teats by their mouths and thus being transported through the mirror-smooth, transparent water. The young, the body length of which appeared to be about $10 \mathrm{~cm}$, were located between the well-spread, kicking hind legs of the female, neatly positioned in a two-abovetwo arrangement and being dragged along in $1.2 \mathrm{~m}$ deep water. They were largely covered by a coarse, sooty hair which they have by the fifth day after birth. By the 14th to 16 th days, when the eyes open this coat has been replaced by a finer, grey one. ${ }^{1}$ The pinkish-white plantar surfaces of the hind feet of the young were easily observed. The legs were not seen to contribute to the locomotion in any way. No air bubbles were released during the time of observation, as these young muskrats instinctively held thier breath. According to Banfield the young are weaned between the 21 st and 28th days after birth.?

When the family was first noticed it was located in the deepest pool behind the dam, then traveled about $7 \mathrm{~m}$ into shallower water whereupon the female gave a powerful kick, turned and plunged downward into a cloud of loose organic debris and sparse bottom vegetation. Approximately $1 \mathrm{~min}$. later she reappeared swimming west from where the family had disappeared. Only three young could be seen attached to the female's teats. The family moved toward the west end of the dam along the same route which had been followed previously and at about the same depth. The family disappeared into what appeared to be a tunnel which no doubt led to the den in the dam. The second observation of the muskrat family covered about $14 \mathrm{~m}$ and took about 18-20 seconds. The bottom of the impoundment where the female had disappeared in the initial sighting was examined but no discernible tunnel or hole could be found although when last seen the female was angling toward the dam.

The absence of the Muskrats for about 1 min. between the end of the initial sighting and the reappearance raises the question of their whereabouts during this time. If the female went to another den in the dam, did the young retain their hold on the teats of did they release it and then begin nursing again? Did the students moving about on the dam cause a repeat of the whole procedure? Did the family actually remain underwater for the duration of $1 \mathrm{~min}$. before proceeding back to the original den? What happened to the apparently missing single young? If it released its hold in open water it probably would have risen to the surface. Possibly it was dislodged in a tunnel and drowned. If the female was flushed from a second den, it may have been left behind. If so, would the female retrieve it? 
Inquiries were made as to the possible uniqueness of this observation. Biologists, conservation officers, naturalists and trappers of considerable experience were consulted, but none had ever even heard of such a case. Dr. Robert Wrigley, Curator of Birds and Mammals and Director of the Manitoba Museum of Man and Nature similarly stated that he had never heard of such an observation (pers. comm., 1985). He noted however, that terrestrial nursing rodents when suddenly alarmed will rush off with the young dangling from the teats. I once observed a Deer Mouse drag several young through the grass after I lifted a board under which the female had been nursing the young in their nest. No doubt this nursing Muskrat was suddenly alarmed as the students walked out onto the Beaver dam.

Wrigley pointed out that the procedure seems to have adaptive value in removing the young from a dangerous situation. This of course, would be particularly true if the female had a safe place or at least some cover to which the young could be dragged. In this situation, involving a semiaquatic rodent, the survival value might be questioned. If the fleeing, nursing female was reacting to a real predator attempting to gain access to the den, the response probably would be advantageous despite the fact that, in this case, she may have lost one young. On the other hand, the fact that one young may have been lost due to no real danger suggests that this response may not always be adaptive, such as in this unnatural instance.

\section{Acknowledgements}

I would like to thank the following people for responding to my inquiries concerning possible similar observations and remarks: Ray Cooley, Robert Nero, Cathy Newcastle, John E. Walley and Robert Wrigley.

BANFIELD, A.W.F. 1974 The mammals of Canada. University of Toronto Press, Toronto.

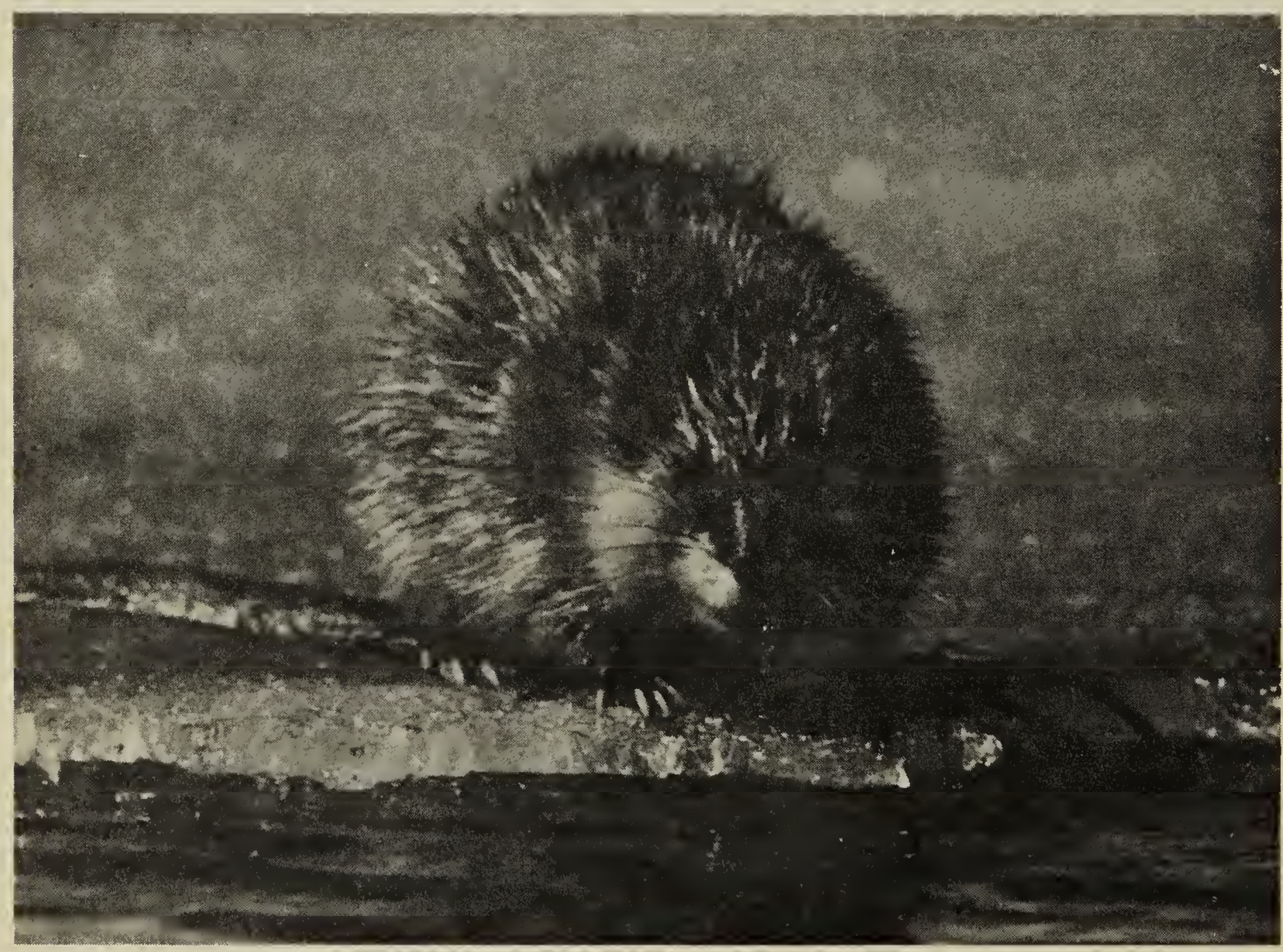




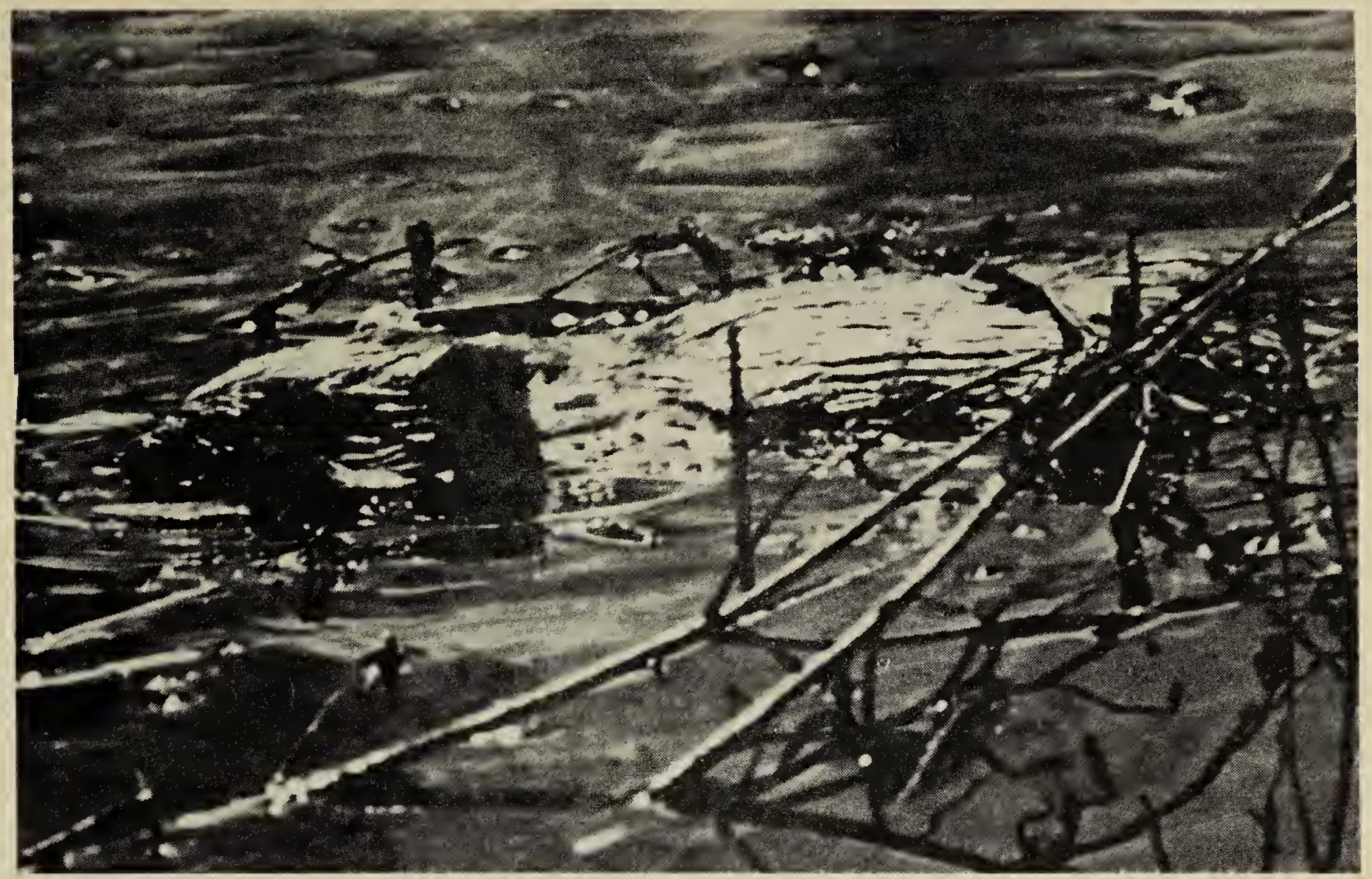

Beaver

F.A. Switzer

\section{BEAVER SWIMS UP WATERFALL}

\section{COLLEEN GERWING, 3 - 510 11th Street East, Saskatoon, Saskatchewan. S7N 0G2}

At dusk on a day in the third weekend in May I was paddling alone on a lake in northern Saskatchewan. I approached a break in a Beaver dam and saw what looked like a Muskrat hydroplaning towards me. I was surprised at how close it came to the canoe, but it gave me a chance to see that it was a fish that had come up the little waterfalls created by the break. The break in the dam was about 15 in. across; water dropped about 20 in. into a pool below. This pool was held by a rough secondary dam which fed a moderately moving creek. I halted by the dam and watched another fish try five times before making it from stream to lake.

For a long time nothing happened, until a Great Blue Heron hurtled into a nearby spruce. I was distracted from the heron by a variety of ducks and a small Beaver which seemed to resent my presence. They all disappeared and I focused back on the heron. Again the Beaver came nearby but was quickly frightened off by the slightest movement. Just as the heron flew away I heard some gurgling and plopping at the little falls. I looked there just in time to see this same Beaver swimming upstream just as the fish had done. It had to struggle, but made it up the first time, then swam away in a hurry, head above water.

I have never heard of Beaver travelling up very strong currents or falls, and I was very surprised that this one had taken the chance when it was aware of my close presence. At the end of the dam there was a short well-used overland route it could have taken, much farther away from me.

Beaver are timid in the wild while also displaying curiosity and mischief. Perhaps this yearling had just that extra sense of adventure. 